Published in final edited form as:

Oral Oncol. 2015 April ; 51(4): 383-388. doi:10.1016/j.oraloncology.2014.12.013.

\title{
A randomized, phase 2 trial of docetaxel with or without PX-866, an irreversible oral phosphatidylinositol 3-kinase inhibitor, in patients with relapsed or metastatic head and neck squamous cell cancer
}

\author{
Antonio Jimeno ${ }^{a,{ }^{*}}$, Julie E. Bauman ${ }^{b}$, Charles Weissman ${ }^{c}$, Douglas Adkins ${ }^{d}$, Ian \\ Schnadige,f ${ }^{e}$ Patrice Beauregard ${ }^{g}$, Daniel W. Bowles ${ }^{a, h}$, Alexander Spira $^{\mathrm{i}, f}$, Benjamin Levy $^{\mathrm{j}}$, \\ Nagashree Seetharamu ${ }^{k}$, Diana Hausman', Luke Walker', Charles M. Rudin ${ }^{m}$, and Keisuke \\ Shirai ${ }^{\mathrm{n}}$ \\ aUniversity of Colorado School of Medicine, Aurora, CO, United States \\ bUniversity of Pittsburgh Cancer Institute, Pittsburgh, PA, United States \\ 'New York Hematology, New York, NY, United States \\ dWashington University, St. Louis, MO, United States \\ éCompass Oncology, Tualatin, OR, United States \\ fUS Oncology Research, The Woodlands, TX, United States \\ ${ }^{9} \mathrm{CHUS}$ Hôpital Fleurimont, Quebec, Canada \\ hDenver Veterans Affairs Medical Center, Denver, CO, United States \\ 'Virginia Cancer Specialists, Fairfax, VA, United States \\ 'Beth Israel Hospital, St. Luke's Hospital, Mount Sinai Health System, New York, NY, United \\ States \\ kNew York University, New York, NY, United States \\ 'Oncothyreon Inc., Seattle, WA, United States \\ mJohns Hopkins University, Baltimore, MD, United States \\ ${ }^{n}$ Medical University of South Carolina, Charleston, SC, United States
}

\section{SUMMARY}

Introduction-The phosphotidylinositol-3 kinase (PI3K)/serine-threonine kinase (AKT)/ mammalian target of rapamycin (mTOR) signaling pathway is frequently altered in head and neck squamous cell cancer (HNSCC). PX-866 is an oral, irreversible, pan-isoform inhibitor of PI3K. Preclinical models revealed synergy with docetaxel and a phase 1 trial demonstrated tolerability of

*Corresponding author at: University of Colorado School of Medicine, Division of Medical Oncology, 12801 East 17th Avenue, MS8117, Aurora, CO 80045, United States. antonio.jimeno@ucdenver.edu (A. Jimeno). 
this combination. This randomized phase 2 study evaluated PX-866 combined with docetaxel in patients with advanced, refractory HNSCC.

Methods-Patients with locally advanced, recurrent or metastatic HNSCC who had received at least one and no more than two prior systemic treatment regimens were randomized (1:1) to a combination of docetaxel (75 mg/m² IV every 21 days) with or without PX-866 (8 mg PO daily; Arms A and B, respectively). The primary endpoint was progression free survival (PFS).

Secondary endpoints included objective response rate (RR), overall survival (OS), toxicity, and correlation of biomarker analyses with efficacy outcomes.

Results-85 patients were enrolled. There was a non-significant improvement in response rate in the combination arm (14\% vs. 5\%; $P=0.13)$. Median PFS was 92 days in Arm A and 82 days in Arm B $(P=0.42)$. There was no difference in OS between the two arms (263 vs. 195 days; $P=$ 0.62 ). Grade 3 or higher adverse events were infrequent, but more common in the combination arm with respect to diarrhea ( $17 \%$ vs. $2 \%$ ), nausea (7\% vs. $0 \%$ ), and febrile neutropenia ( $21 \%$ vs. $5 \%$ ); grade 3 or higher anemia was more frequent in arm B (7\% vs. 27\%). PIK3CA mutations or PTEN loss were infrequently observed.

Conclusion-The addition of PX-866 to docetaxel did not improve PFS, RR, or OS in patients with advanced, refractory HNSCC without molecular pre-selection.

\section{Keywords}

PIK3CA; PI3K; Docetaxel; Head and neck squamous cell cancer

\section{Introduction}

The phosphotidylinositol-3 kinase (PI3K)/serine-threonine kinase (AKT)/mammalian target of rapamycin (mTOR) signaling pathway is frequently altered in human cancers, leading to cell proliferation, enhanced expression of survival genes and decreased expression of proapoptotic factors [1]. PI3K is an intracellular kinase comprised of the p110a, p110 p110 catalytic subunits, and a p85 regulatory subunit; mutations to p110a and p85 are oncogenic [2,3]. Activating mutations to PIK3CA, the gene encoding the p110a catalytic subunit of PI3K, are found in several tumor types, including glioblastoma (27\%), breast (18\%), colorectal (16\% of non-hypermutated tumors), cervical (33\%), head and neck squamous cell cancer (HNSCC; 6-8\%), and non-small cell lung cancer (NSCLC; 2-6\%) [2,4-9]. Increased PIK3CA copy numbers are seen in prostate cancer (28\%), squamous histology NSCLC (33\%), and HNSCC (45\%) [10-12]. The phosphatase and tensin homolog (PTEN) tumor suppressor gene, which inhibits PI3K signaling, may be lost via deletion (25\% of melanoma, breast, and prostate cancers), mutation, or epigenetic suppression [1316]. Lastly, upstream growth factor receptors that activate PI3K signaling, such as epidermal growth factor receptor (EGFR) and insulin-like growth factor receptor, are often overexpressed in cancer $[17,18]$.

PX-866 is a novel oral, pan-isoform inhibitor of PI3K [19]. In a phase 1 study, both PX-866 and docetaxel were given at their single agent maximal tolerated doses in patients with advanced cancers [20]. The majority of adverse events (AE) were gastrointestinal and grade $\preceq$ similar to the single agent PX-866 trial [21]. Best response per Response Evaluation 
Criteria in Solid Tumors (RECIST) 1.1 [22] was stable disease in over 50\% of evaluable patients at Week 6. Consistent with other studies investigating PI3K inhibitors, PIK3CA mutations were associated with longer duration of stable disease, but this was not statistically significant [21,23].

PX-866 had substantial antitumor efficacy in preclinical studies using a HNSCC patient derived xenograft (PDX) model that occurred both in cases with and without a PIK3CA activating genetic events [24]; in this same model an additive/synergistic effect was observed in vivo with docetaxel (unpublished data). Docetaxel has been shown to be an active agent in relapsed/metastatic (R/M) HNSCC in weekly and every 3 week regimens [25,26], is considered an appropriate second/third line therapy by the National Comprehensive Cancer Network (NCCN) guidelines, and has a toxicity profile that does not overlap with that of PX-866.

Therefore, we conducted an open-label, randomized, phase 2 trial comparing docetaxel alone versus docetaxel plus PX-866 without the possibility of cross-over in patients with $\mathrm{R} / \mathrm{M}$ HNSCC in the second or third-line setting.

\section{Patient and methods}

\section{Eligibility criteria}

Subjects had R/M HNSCC for which they had received 1-2 prior systemic therapies, including up to one platinum-based chemotherapy regimen. Other key inclusion criteria were age $\geq 18$ years, measurable disease by RECIST 1.1 criteria [22], ECOG performance status $0-1$, life expectancy $\geq 3$ months, and adequate hematologic, hepatic and renal function. Treatment with any systemic anti-cancer or radiation therapy was not allowed within 4 weeks of study drug dosing. Patients with adequately treated and stable brain metastases were eligible.

Salient exclusion criteria included known HIV infection; medical, social or psychological factors affecting safety or compliance; grade $\geq 2$ neuropathy; history of hypersensitivity to docetaxel or other drugs formulated with polysorbate; pregnant/breastfeeding; prior docetaxel for R/M HNSCC or within 6 months of enrollment in the curative setting; or any prior treatment with a PI3K inhibitor. Each center's institutional review board granted approval and written informed consent was mandatory.

\section{Treatment and efficacy assessments}

Patients were randomized to docetaxel $75 \mathrm{mg} / \mathrm{m}^{2} \mathrm{IV}$ once every 21 days with or without PX-866 $8 \mathrm{mg}$ by mouth daily in a 1:1 fashion without stratification factors. Colony stimulating factors and anti-emetics were permitted in any cycle according to institutional guidelines. All patients received dexamethasone $8 \mathrm{mg}$ orally twice daily for 3 days starting the day before docetaxel administration. Patients were evaluated for progression every 2 cycles. Patients continued therapy as long as they had stable disease or better per RECIST 1.1 criteria and lacked unacceptable toxicity or withdrawal of consent. Patients in the combination arm were allowed to continue PX-866 alone after discontinuation of docetaxel. 


\section{Safety assessment}

Safety assessments included vital signs, laboratory assessments and physical exams. Adverse events (AEs) were assessed using the NCI Common Terminology Criteria for Adverse Events (CTCAE) version 4.02. Up to two dose reductions were allowed for docetaxel ( 60 and $45 \mathrm{mg} / \mathrm{m}^{2}$ ) and three dose reductions for PX-866 (6, 4 and $2 \mathrm{mg}$ per day). Subjects requiring additional dose reductions of PX-866 were removed from study. Study drugs were discontinued if treatment needed to be delayed by more than two weeks.

\section{Biomarker measurements}

Optional archival tumor specimens were centrally evaluated for PIK3CA and $K R A S$ mutations, p16 and PTEN expression by immunohistochemistry (IHC) using a standard clinical assay or as previously described [21,27].

\section{Statistics}

The primary endpoint of this study was progression-free survival (PFS) and secondary endpoints were objective response rate (ORR), incidence and severity of AEs, overall survival (OS) and exploratory endpoints of biomarker correlations with efficacy. A docetaxel alone control of median PFS of 3 months was assumed for the HNSCC study population. With a 1-sided 0.20 false positive error rate, a projected 1-year enrollment period with an additional 0.5 years of follow-up prior to analysis and a control over experimental hazard ratio of 1.5 , a total of 80 patients were required for the log-rank test with 0.80 power to detect a statistically significant benefit in terms of lengthening PFS of the combination arm of docetaxel plus PX-866 versus docetaxel alone.

\section{Results}

\section{Patient characteristics}

Eighty-five patients were enrolled between November 2011 and June 2013. 42 and 43 patients were randomized to the PX-866 plus docetaxel (arm A) and docetaxel alone group (arm B), respectively. Baseline characteristics were well balanced between the two arms. The groups were similar with respect to numbers of prior systemic therapies and median time since diagnosis Table 1.

\section{Treatment delivered}

In arm A, 42 patients (100\%) received at least one dose of PX-866 and/or docetaxel, while 41 patients $(95 \%)$ in arm B received at least one dose of docetaxel. The median number of docetaxel cycles administered was 3.5 (range, 1-13) and 4 (range, 1-12) in arms A and B, respectively. The dose intensity of docetaxel was equivalent, with $70 \mathrm{mg} / \mathrm{m}^{2} /$ cycle and 72 $\mathrm{mg} / \mathrm{m}^{2} /$ cycle in arms A and B, respectively. Thirty-four patients (81\%) experienced a total of 97 dose interruptions or modifications of PX-866, with 61 (63\%) of disruptions due to adverse events. The most common reason for PX-866 dose disruptions was diarrhea, which is consistent with the single agent toxicity of this agent. A total of 56 patients (29 in arm A and 27 in arm B) were taken off study due to disease progression. 


\section{Efficacy evaluation}

Sixty-eight (80\%) patients were evaluable for response as measured by RECIST 1.1 (35 in Arm A, 33 in Arm B). There were no complete responses (CR) in either arm. There were 6 $(14 \%)$ and $2(5 \%)$ confirmed partial responses (PR) in arms A and B, respectively, a difference that was not statistically significant $(P=0.13)$. There was one additional unconfirmed PR in each arm. There were $9(21 \%)$ and $8(19 \%)$ patients receiving 7 or more cycles in arms A and $\mathrm{B}$, respectively $(P=0.79)$. There were no differences in the disease control rates $(\mathrm{CR}+\mathrm{PR}+$ stable disease $[\mathrm{SD}])$ after 2 cycles that were $57 \%$ and $54 \%$ for arms A and B, respectively (Table 2). Median PFS was 92 days (95\% CI 46-119) for arm A and 82 days (95\% CI 47-96) for arm B ( $P=0.42$, Fig. 1). The PFS estimates at 3 months were 50\% (95\% CI 33-65\%) for arm A and 38\% (95\% CI 23-53\%) for arm B, respectively. The hazard ratio for PFS was 0.95 (95\% CI 0.57-1.58). Median OS was 263 days in arm A (95\% CI 125-383) and 195 days in arm B (95\% CI 121-NR; $P=0.62$, Fig. 2).

\section{Human papillomavirus (HPV) and treatment efficacy}

HPV testing was conducted centrally. Of the 49 patients with available tissue for analysis, 25 patients (51\%) were HPV positive and 24 (49\%) were HPV negative (Table 3). There were $15 \mathrm{HPV}$ positive patients randomized to arm $\mathrm{A}$, versus 10 that were allocated to arm $\mathrm{B}$, an imbalance that was not significant $(P=0.24)$. Out of the 17 patients that received therapy for 7 or more cycles, 7 (41\%) were HPV positive, 4 (24\%) were HPV negative, and $6(35 \%)$ had an unknown status. Out of the 8 patients that had a confirmed PR, 4 (50\%) were HPV positive, 1 (13\%) was HPV negative, and $3(37 \%)$ had an unknown status.

\section{Genomics}

Of the 49 patients whose archival tumors were analyzed 4 (8\%) had PIK3CA exon 9 mutations (3 G1633A, 1 A1634G; 3 in arm A and 1 in arm B; 3 HPV positive, $1 \mathrm{HPV}$ negative) while none had $K R A S$ mutations. PTEN expression was reduced or absent in 3 patients ( 2 in arm A, 1 in arm B; $2 \mathrm{HPV}$ positive, $1 \mathrm{HPV}$ negative). PIK3CA mutation, and PTENIHC could not be correlated with PFS, ORR, or OS due to their rarity.

\section{Safety and tolerability}

Eighty-three enrolled patients received at least one treatment on protocol and were considered evaluable for safety (all 42 in arm A and 41 in arm B). In both arms most adverse events were $\underline{s}$ (Table 4). There were more treatment related adverse events in arm A (all grade, 281; grade 3-5, 85) compared to arm B (all grade, 186; grade 3-4, 43). Specifically in arm A there was more diarrhea (64\% vs. $22 \%$ ), vomiting (57\% vs. $15 \%$ ), nausea (50\% vs. $29 \%$ ), electrolyte deficits (hypomagnesemia and hyponatremia both $19 \%$ in arm A and 7\% in arm B), rash (14\% vs. $0 \%)$, and ALT/AST elevation (17\% vs. $0 \%)$. There were similar rates of infections (pneumonia and candidiasis at $17 \%$ and $12 \%$ in both groups, respectively) between both arms. In terms of hematological toxicity, febrile neutropenia was more common in arm A ( $21 \%$ vs.5\%), but with more reported anemia in arm B (14\% vs. $29 \%)$. Six patients in arm A died during the study (1 related to toxicity; pneumonia) while 2 patients in arm B passed away during treatment. Three patients in arm A withdrew due to AEs while 2 patients in arm B were taken off study due to toxicity. 


\section{Discussion}

This manuscript reports on a prospective, randomized study of docetaxel plus/minus a small molecule inhibitor targeted against PI3K in relapsed or metastatic HNSCC patients.

Although the combination failed to improve outcomes compared to docetaxel alone, this is one of the first prospective trials in the HPV era, and it showed a higher proportion of HPV positive patients over HPV negative than expected, which has profound implications in trial design. It also assessed a PI3K inhibitor targeting the protein product of PIK3CA, the gene with the highest rate of activating mutations in HNSCC.

The primary question of this trial was answered unequivocally; the addition of PX-866 to docetaxel failed to improve PFS, ORR, or OS in patients with R/M HNSCC. The higher observed response rate was not statistically significant $(P=0.13)$, though this may be a reflection of a small sample size. However the PFS was only 10 days longer in the combination arm, and OS estimates were non-significant. It is possible that the lack of clinical benefit resulted from lack of molecular pre-selection in this study, as very few tumors harbored genetic alterations (PIK3CA mutations, PTEN loss) thought to predict sensitivity to PI3K inhibitors.

While it has been difficult to identify predictive biomarkers across all tumor types for this class of drugs, preclinical and clinical data suggest that PI3K pathway activation may correlate with sensitivity to PI3K inhibitors [24,28-30]. PX-866 has been efficacious in a HNSCC PDX in cases with PIK3CA activating mutations or gene amplification, although activity was also seen in cases without any such genetic events [24]. The data from the PX-866 clinical experience as well for other PI3K inhibitors suggest that currently identifiable pathway alterations are not always sufficient to predict efficacy [31].

It is interesting to note that in this dataset of R/M HNSCC patients, $51 \%$ of those where HPV status could be tested were positive. We did not identify significant differences in treatment-related efficacy (either by response rate or by patients receiving more than 6 cycles, a surrogate for benefit) between HPV positive and HPV negative patients, but this trial was not powered to address sub-group analyses.

While the addition of PX-866 to docetaxel was reasonably well tolerated, toxicity appeared to be more pronounced in the combination arm. This was particularly evident in the incidence of GI toxicities (nausea, vomiting, and diarrhea), leading to electrolyte imbalances. The data of this trial pertaining hematological toxicity is less consistent, since there was more neutropenia but less anemia in the combination arm compared to docetaxel alone; we do not have a readily available explanation for this dichotomy. Many of AEs are consistent with other phase $1 / 2$ studies evaluating PI3K inhibitors including our own phase 1 study [20], and the previously reported "twin" study in non-small cell lung cancer [32]. The side effect profile was remarkably similar in our trial in HNSCC compared to the NSCLC study, including the toxicity imbalances with the exception of neutropenia. To date, rash, hyperglycemia, and transaminase elevations appear to be class effects of PI3K/AKT/mTOR inhibition, although gastrointestinal side effects have been reported in studies as well [33]. However, in addition to PX-866 other PI3K inhibitors such as XL147 have reported a 
relative lack of glycemic toxicity [31]. Interestingly, despite more frequent adverse events in the combination arm, the proportion of patients being taken off study due to toxicity was similar between arms suggesting that the toxicity was manageable; similarly, the docetaxel dose intensity was similar between arms, indicating that combination therapy did not lead to less intense standard therapy administration.

In summary, the addition of PX-866 to docetaxel did not improve clinical outcomes over docetaxel alone in a molecularly unselected population of R/M HNSCC patients. Further investigations with PI3K inhibitors in HNSCC should focus on appropriate biomarker or histology selection to maximize the chances of clinical benefit. While PIK3CA activating genetic events may predict sensitivity to this class of drugs, a solid link has been elusive, challenging the hypothesis that PIK3CA mutations alone support oncogenesis and tumor growth in contrast to other oncogenic mutations. Further exploration is needed to better define molecularly those patients most likely to derive a benefit from such agents, since it is likely that associated genetic events may help predict their utility.

\section{Acknowledgments}

\section{Conflict of interest}

Dr. Jimeno has received laboratory research support from Oncothyreon Inc. Dr. Bauman received grant support from Oncothyreon, Bristol-Myers Squibb, Genentech and Lilly, and is a paid consultant for Aveo. Dr. Levy is a paid consultant and receives speakers honoraria from Boehringer Ingelheim, Eli Lilly, Genentech, and Pfizer. Dr. Walker and Dr. Hausman are full time employees of Oncothyreon. Dr. Walker has received travel support to meetings for the study as well as travel unrelated to the study. Dr. Rudin is a consultant for AbbVie, Aveo, Boehringer Ingelheim, GlaxoSmithKline, and Merck.

Funding

This clinical trial was sponsored by Oncothyreon Inc. No funding was received from the NIH, Wellcome Trust or HHMI.

\section{References}

1. Courtney KD, Corcoran RB, Engelman JA. The PI3K pathway as drug target in human cancer. J Clin Oncol. 2010; 28:1075-1083. [PubMed: 20085938]

2. Samuels Y, Ericson K. Oncogenic PI3K and its role in cancer. Curr Opin Oncol. 2006; 18:77-82. [PubMed: 16357568]

3. Jaiswal BS, Janakiraman V, Kljavin NM, Chaudhuri S, Stern HM, Wang W, et al. Somatic mutations in p85alpha promote tumorigenesis through class IA PI3K activation. Cancer Cell. 2009; 16:463474. [PubMed: 19962665]

4. Levine DA, Bogomolniy F, Yee CJ, Lash A, Barakat RR, Borgen PI, et al. Frequent mutation of the PIK3CA gene in ovarian and breast cancers. Clin Cancer Res. 2005; 11:2875-2878. [PubMed: 15837735]

5. Miyake T, Yoshino K, Enomoto T, Takata T, Ugaki H, Kim A, et al. PIK3CA gene mutations and amplifications in uterine cancers, identified by methods that avoid confounding by PIK3CA pseudogene sequences. Cancer Lett. 2008; 261:120-126. [PubMed: 18180098]

6. Hayes MP, Wang H, Espinal-Witter R, Douglas W, Solomon GJ, Baker SJ, et al. PIK3CA and PTEN mutations in uterine endometrioid carcinoma and complex atypical hyperplasia. Clin Cancer Res. 2006; 12:5932-5935. [PubMed: 17062663]

7. Agrawal N, Frederick MJ, Pickering CR, Bettegowda C, Chang K, Li RJ, et al. Exome sequencing of head and neck squamous cell carcinoma reveals inactivating mutations in NOTCH1. Science. 2011; 333:1154-1157. [PubMed: 21798897] 
8. Stransky N, Egloff AM, Tward AD, Kostic AD, Cibulskis K, Sivachenko A, et al. The mutational landscape of head and neck squamous cell carcinoma. Science. 2011; 333:1157-1160. [PubMed: 21798893]

9. Muzny DM, Bainbridge MN, Chang K, Dinh HH, Drummond JA, et al. Comprehensive molecular characterization of human colon and rectal cancer. Nature. 2012; 487:330-337. [PubMed: 22810696]

10. Agell L, Hernandez S, Salido M, de Muga S, Juanpere N, Arumi-Uria M, et al. PI3K signaling pathway is activated by PIK3CA mRNA overexpression and copy gain in prostate tumors, but PIK3CA, BRAF, KRAS and AKT1 mutations are infrequent events. Mod Pathol. 2011; 24:443452. [PubMed: 21113138]

11. Yamamoto H, Shigematsu H, Nomura M, Lockwood WW, Sato M, Okumura N, et al. PIK3CA mutations and copy number gains in human lung cancers. Cancer Res. 2008; 68:6913-6921. [PubMed: 18757405]

12. Morris LG, Taylor BS, Bivona TG, Gong Y, Eng S, Brennan CW, et al. Genomic dissection of the epidermal growth factor receptor (EGFR)/PI3K pathway reveals frequent deletion of the EGFR phosphatase PTPRS in head and neck cancers. Proc Natl Acad Sci USA. 2011; 108:19024-19029. [PubMed: 22065749]

13. Carracedo A, Pandolfi PP. The PTEN-PI3K pathway: of feedbacks and cross-talks. Oncogene. 2008; 27:5527-5541. [PubMed: 18794886]

14. Tokunaga E, Oki E, Kimura Y, Yamanaka T, Egashira A, Nishida K, et al. Coexistence of the loss of heterozygosity at the PTEN locus and HER2 overexpression enhances the Akt activity thus leading to a negative progesterone receptor expression in breast carcinoma. Breast Cancer Res Treat. 2007; 101:249-257. [PubMed: 17006756]

15. McLendon R, Friedman A, Bigner D, Van Meir EG, Brat DJ, et al. Comprehensive genomic characterization defines human glioblastoma genes and core pathways. Nature. 2008; 455:10611068. [PubMed: 18772890]

16. Pesche S, Latil A, Muzeau F, Cussenot O, Fournier G, Longy M, et al. PTEN/MMAC1/TEP1 involvement in primary prostate cancers. Oncogene. 1998; 16:2879-2883. [PubMed: 9671408]

17. Bowles DW, Jimeno A. New phosphatidylinositol 3-kinase inhibitors for cancer. Expert Opin Investig Drugs. 2011; 20:507-518.

18. Zhang Y, Moerkens M, Ramaiahgari S, de Bont H, Price L, Meerman J, et al. Elevated insulin-like growth factor 1 receptor signaling induces antiestrogen resistance through the MAPK/ERK and PI3K/Akt signaling routes. Breast Cancer Res. 2011; 13:R52. [PubMed: 21595894]

19. Wipf P, Minion DJ, Halter RJ, Berggren MI, Ho CB, Chiang GG, et al. Synthesis and biological evaluation of synthetic viridans derived from C(20)-heteroalkylation of the steroidal PI-3-kinase inhibitor wortmannin. Org Biomol Chem. 2004; 2:1911-1920. [PubMed: 15227545]

20. Bowles DW, Ma WW, Senzer N, Brahmer JR, Adjei AA, Davies M, et al. A multicenter phase 1 study of PX-866 in combination with docetaxel in patients with advanced solid tumours. Br J Cancer. 2013; 109:1085-1092. [PubMed: 23942080]

21. Hong DS, Bowles DW, Falchook GS, Messersmith WA, George GC, O’Bryant CL, et al. A multicenter phase I trial of PX-866, an oral irreversible phosphatidylinositol 3-kinase inhibitor, in patients with advanced solid tumors. Clin Cancer Res. 2012; 18:4173-4182. [PubMed: 22693357]

22. Eisenhauer EA, Therasse P, Bogaerts J, Schwartz LH, Sargent D, Ford R, et al. New response evaluation criteria in solid tumours: revised RECIST guideline (version 1.1). Eur J Cancer. 2009; 45:228-247. [PubMed: 19097774]

23. Bendell JC, Rodon J, Burris HA, de Jonge M, Verweij J, Birle D, et al. Phase I, dose-escalation study of BKM120, an oral pan-class I PI3K inhibitor, in patients with advanced solid tumors. J Clin Oncol. 2012; 30:282-290. [PubMed: 22162589]

24. Keysar SB, Astling DP, Anderson RT, Vogler BW, Bowles DW, Morton JJ, et al. A patient tumor transplant model of squamous cell cancer identifies PI3K inhibitors as candidate therapeutics in defined molecular bins. Mol Oncol. 2013; 7:776-790. [PubMed: 23607916]

25. Catimel G, Verweij J, Mattijssen V, Hanauske A, Piccart M, Wanders J, et al. Docetaxel (Taxotere): an active drug for the treatment of patients with advanced squamous cell carcinoma of the head and neck. EORTC Early Clinical Trials Group. Ann Oncol. 1994; 5:533-537. [PubMed: 7918125] 
26. Guardiola E, Peyrade F, Chaigneau L, Cupissol D, Tchiknavorian X, Bompas E, et al. Results of a randomised phase II study comparing docetaxel with methotrexate in patients with recurrent head and neck cancer. Eur J Cancer. 2004; 40:2071-2076. [PubMed: 15341981]

27. Bowles DW, Ma WW, Senzer N, Brahmer JR, Adjei AA, Davies M, et al. A multicenter phase 1 study of PX-866 in combination with docetaxel in patients with advanced solid tumours. Br J Cancer. 2013

28. Janku F, Tsimberidou AM, Garrido-Laguna I, Wang X, Luthra R, Hong DS, et al. PIK3CA mutations in patients with advanced cancers treated with PI3K/AKT/ mTOR axis inhibitors. Mol Cancer Ther. 2011; 10:558-565. [PubMed: 21216929]

29. Spoerke JM, O’Brien C, Huw L, Koeppen H, Fridlyand J, Brachmann RK, et al. Phosphoinositide 3-kinase (PI3K) pathway alterations are associated with histologic subtypes and are predictive of sensitivity to PI3K inhibitors in lung cancer preclinical models. Clin Cancer Res. 2012; 18:67716783. [PubMed: 23136191]

30. Turke AB, Engelman JA. PIKing the right patient. Clin Cancer Res. 2010; 16:3523-3525. [PubMed: 20538763]

31. Shapiro GI, Rodon J, Bedell C, Kwak EL, Baselga J, Brana I, et al. Phase I safety, pharmacokinetic, and pharmacodynamic study of SAR245408 (XL147), an oral pan-class I PI3K inhibitor, in patients with advanced solid tumors. Clin Cancer Res. 2014; 20:233-245. [PubMed: 24166903]

32. Levy B, Spira A, Becker D, Evans T, Schnadig I, Camidge DR, et al. A randomized, phase 2 trial of Docetaxel with or without PX-866, an irreversible oral phosphatidylinositol 3-kinase inhibitor, in patients with relapsed or metastatic non-small-cell lung cancer. J Thorac Oncol. 2014; 9:10311035. [PubMed: 24926548]

33. Papadimitrakopoulou V. Development of PI3K/AKT/mTOR pathway inhibitors and their application in personalized therapy for non-small-cell lung cancer. J Thorac Oncol. 2012; 7:13151326. [PubMed: 22648207] 

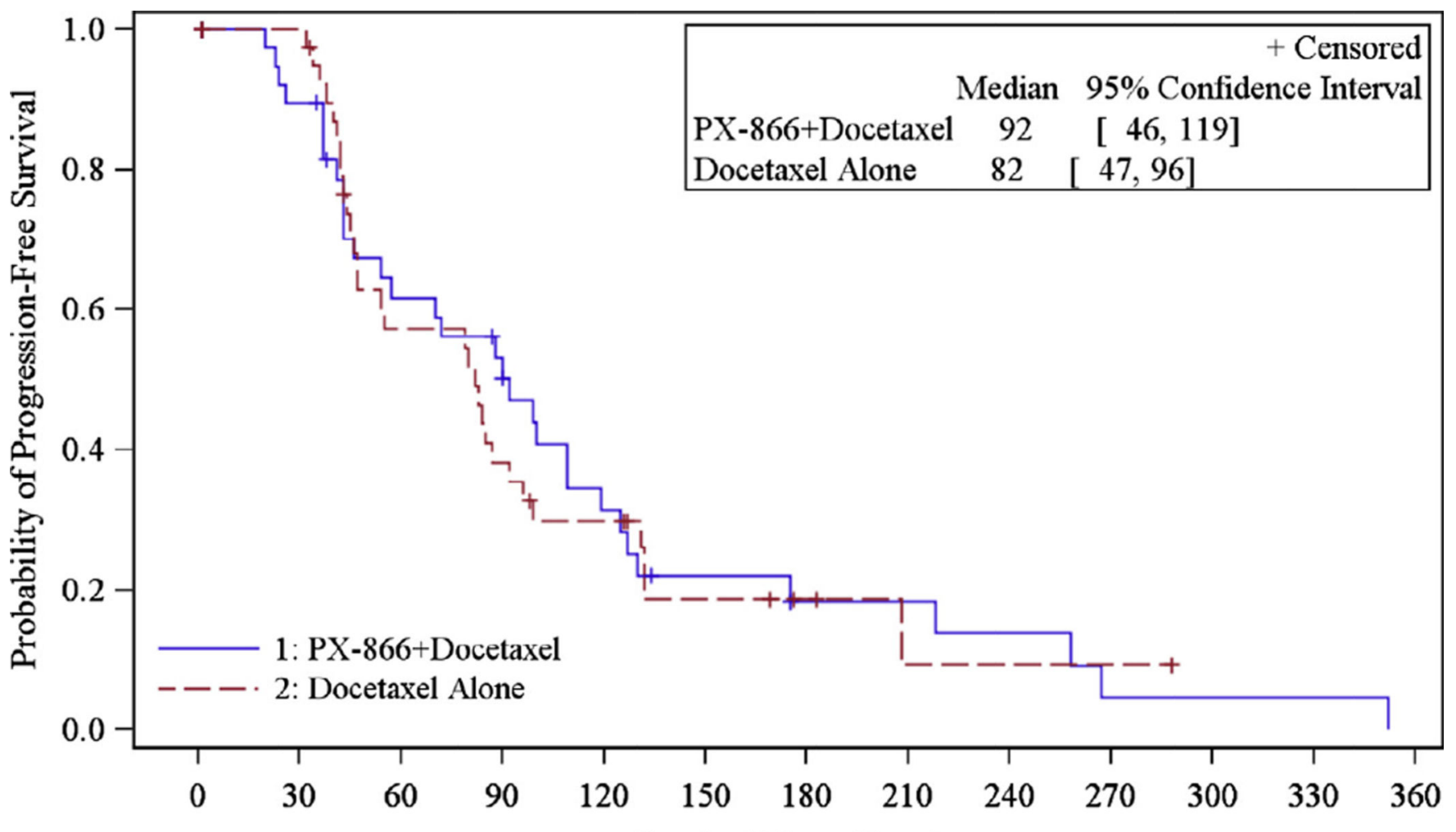

Survival Time (Days)

\begin{tabular}{|c|c|c|c|c|c|c|c|c|c|c|c|c|c|}
\hline 1 & 42 & 34 & 22 & 16 & 10 & 6 & 4 & 4 & 3 & 1 & 1 & 1 & 0 \\
\hline 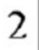 & 43 & 39 & 21 & 14 & 10 & 5 & 3 & 1 & 1 & 1 & 0 & & \\
\hline
\end{tabular}

Fig. 1.

Kaplan-Meier curves for progression free survival (days). 


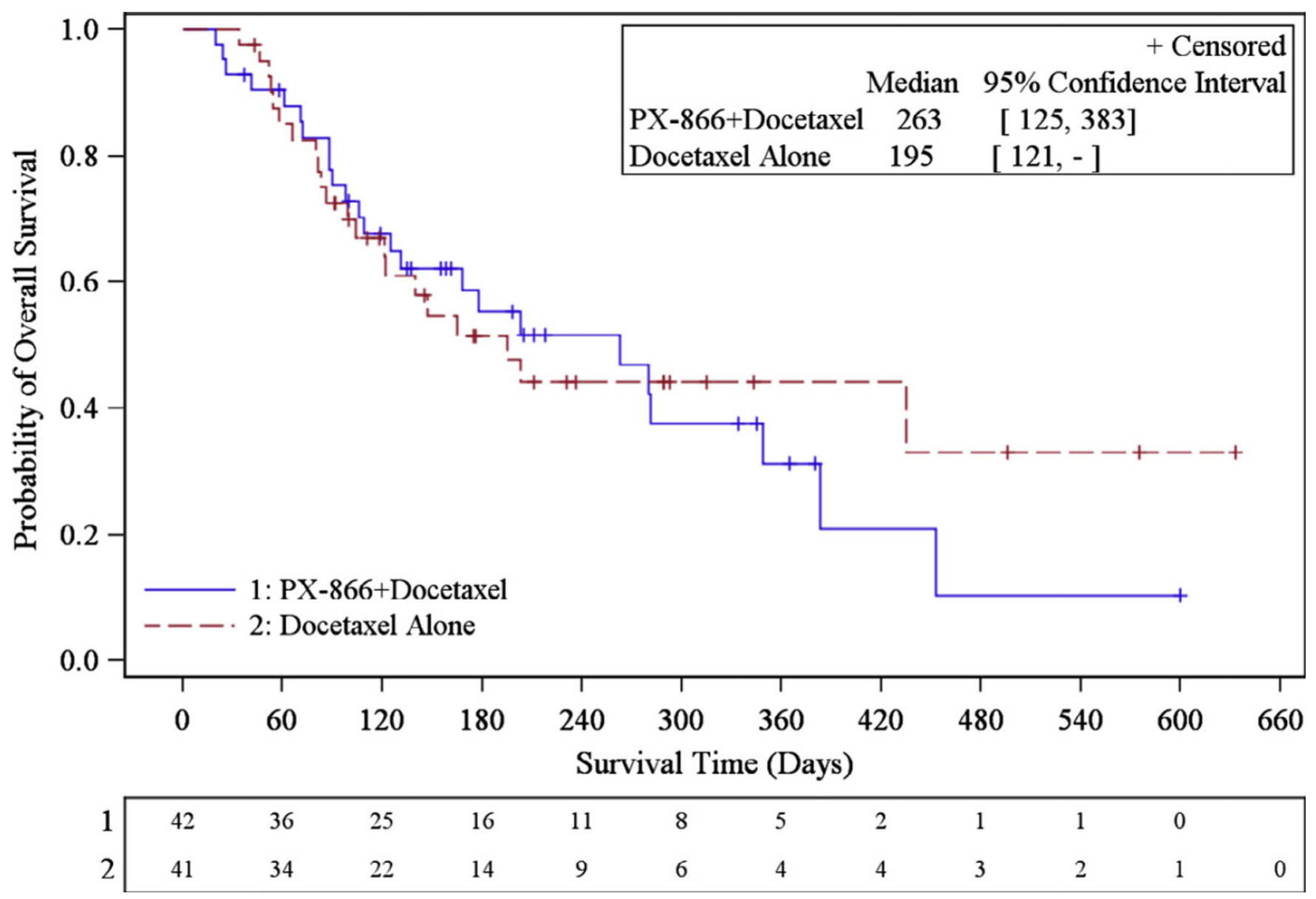

Fig. 2.

Kaplan-Meier curves for overall survival (days). 


\section{Table 1}

Patient characteristics.

\begin{tabular}{lll}
\hline & PX-866 + docetaxel $(\boldsymbol{n}=\mathbf{4 2})$ & Docetaxel $(\boldsymbol{n}=\mathbf{4 3})$ \\
\hline Median age (range) & $62(36-81)$ & $60(40-82)$ \\
SeX & & \\
Female & $4(10 \%)$ & $7(16 \%)$ \\
Male & $38(90 \%)$ & $36(84 \%)$ \\
Ethnicity & & \\
Caucasian & $39(93 \%)$ & $37(86 \%)$ \\
African American & $3(7 \%)$ & $5(12 \%)$ \\
Other & $0(0 \%)$ & $1(2 \%)$ \\
ECOG & & $8(19 \%)$ \\
0 & $12(29 \%)$ & $35(81 \%)$ \\
1 & $30(71 \%)$ & $5 / 9 / 16 / 70$ \\
Stage at diagnosis I/II/III/IV (\%) & $2 / 5 / 14 / 79$ & $1(2 \%) / 42(98 \%)$ \\
Stage at baseline III/IV $(\%)$ & $0(0 \%) / 42(100 \%)$ & $43(100 \%)$ \\
Prior anti-cancer therapy & $42(100 \%)$ & $22(51 \%)$ \\
Systemic therapy & $27(64 \%)$ & $10(23 \%)$ \\
Radiotherapy & $10(24 \%)$ & $37(86 \%)$ \\
Systemic/radiotherapy & $35(83 \%)$ & $1.7(1-4)$ \\
Number of prior systemic therapies mean/range & $1.7(1-4)$ & 20.2 \\
Median time since diagnosis, months & 18.0 & \\
\hline
\end{tabular}

Oral Oncol. Author manuscript; available in PMC 2016 May 05. 
Table 2

\begin{tabular}{|c|c|c|c|}
\hline \multicolumn{4}{|c|}{ te ${ }^{a}$} \\
\hline \multirow{6}{*}{ 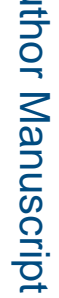 } & & PX-866 + Docetaxel $(n=42)$ & Docetaxel $(n=43)$ \\
\hline & Complete response & 0 & 0 \\
\hline & Partial response & $6(14 \%)$ & $2(5 \%)$ \\
\hline & Stable disease & $18(43 \%)$ & $21(49 \%)$ \\
\hline & Progressive disease & $11(26 \%)$ & $10(23 \%)$ \\
\hline & Not evaluable & $7(17 \%)$ & $10(23 \%)$ \\
\hline & Disease control rate (CR/PR/SD) & $24(57 \%)$ & $23(54 \%)$ \\
\hline
\end{tabular}

${ }^{a}$ Response rate represent best overall response rate (investigator). 


\section{Table 3}

Treatment distribution by HPV status.

\begin{tabular}{|c|c|c|}
\hline & PX-866 + docetaxel $(n=42)$ & Docetaxel $(n=43)$ \\
\hline HPV positive & $15(36 \%)$ & $10(23 \%)$ \\
\hline PIK3CA mutation & $3(8 \%)$ & $0(0 \%)$ \\
\hline 7 or more cycles & $6(14 \%)$ & $1(2 \%)$ \\
\hline Partial response & $3(7 \%)$ & $1(2 \%)$ \\
\hline HPV negative & $12(28 \%)$ & $12(28 \%)$ \\
\hline PIK3CA mutation & $0(0 \%)$ & $1(2 \%)$ \\
\hline 7 or more cycles & $1(2 \%)$ & $3(7 \%)$ \\
\hline Partial response & $1(2 \%)$ & $0(0 \%)$ \\
\hline Not available & $15(36 \%)$ & $21(49 \%)$ \\
\hline PIK3CA mutation & $0(0 \%)$ & $0(0 \%)$ \\
\hline 7 or more cycles & $2(5 \%)$ & $4(9 \%)$ \\
\hline Partial response & $2(5 \%)$ & $1(2 \%)$ \\
\hline
\end{tabular}

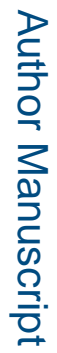


Table 4

Adverse events occurring in $10 \%$ or more of one of the arms.

\begin{tabular}{|c|c|c|c|c|}
\hline \multirow[t]{2}{*}{ Adverse event } & \multicolumn{2}{|c|}{ PX-866 + Docetaxel $(n=42)$} & \multicolumn{2}{|c|}{ Docetaxel alone $(n=41)$} \\
\hline & All grades & Grade $\geq \mathbf{3}$ & All grades & Grade $\geq \mathbf{3}$ \\
\hline \multicolumn{5}{|l|}{ Hematological } \\
\hline Anemia & $6(14 \%)$ & $3(7 \%)$ & $12(29 \%)$ & $11(27 \%)$ \\
\hline Neutropenia & $26(62 \%)$ & $26(62 \%)$ & $16(39 \%)$ & $15(37 \%)$ \\
\hline Thrombocytopenia & $0(0 \%)$ & $0(0 \%)$ & $1(2 \%)$ & $0(0 \%)$ \\
\hline Febrile neutropenia & $9(21 \%)$ & $9(21 \%)$ & $2(5 \%)$ & $2(5 \%)$ \\
\hline \multicolumn{5}{|l|}{ Non-hematological } \\
\hline Abdominal pain & $7(17 \%)$ & $2(5 \%)$ & $1(2 \%)$ & $0(0 \%)$ \\
\hline Diarrhea & $27(64 \%)$ & $7(17 \%)$ & $9(22 \%)$ & $1(2 \%)$ \\
\hline Constipation & $5(12 \%)$ & $0(0 \%)$ & $12(29 \%)$ & $0(0 \%)$ \\
\hline Nausea & $21(50 \%)$ & $3(7 \%)$ & $12(29 \%)$ & $0(0 \%)$ \\
\hline Stomatitis & $7(17 \%)$ & $0(0 \%)$ & $4(10 \%)$ & $2(5 \%)$ \\
\hline Vomiting & $24(57 \%)$ & $2(4 \%)$ & $6(15 \%)$ & $0(0 \%)$ \\
\hline Fatigue & $22(52 \%)$ & $3(7 \%)$ & $20(49 \%)$ & $4(10 \%)$ \\
\hline Peripheral edema & $7(17 \%)$ & $0(0 \%)$ & $3(7 \%)$ & $0(0 \%)$ \\
\hline Candidiasis & $5(12 \%)$ & $0(0 \%)$ & $5(12 \%)$ & $1(2 \%)$ \\
\hline Pneumonia & $7(17 \%)$ & $5(12 \%)$ & $7(17 \%)$ & $4(10 \%)$ \\
\hline Weight loss & $6(14 \%)$ & $0(0 \%)$ & $3(7 \%)$ & $1(2 \%)$ \\
\hline Dehydration & $14(33 \%)$ & $0(0 \%)$ & $7(17 \%)$ & $0(0 \%)$ \\
\hline Hypokalemia & $6(14 \%)$ & $3(7 \%)$ & $2(5 \%)$ & $0(0 \%)$ \\
\hline Hypomagnesemia & $8(19 \%)$ & $0(0 \%)$ & $3(7 \%)$ & $1(2 \%)$ \\
\hline Hyponatremia & $8(19 \%)$ & $6(14 \%)$ & $3(7 \%)$ & $3(7 \%)$ \\
\hline Transaminitis & $7(17 \%)$ & $2(5 \%)$ & $0(0 \%)$ & $0(0 \%)$ \\
\hline Headache & $6(14 \%)$ & $1(2 \%)$ & $3(7 \%)$ & $0(0 \%)$ \\
\hline Insomnia & $9(21 \%)$ & $0(0 \%)$ & $2(5 \%)$ & $0(0 \%)$ \\
\hline Cough & $9(21 \%)$ & $0(0 \%)$ & $7(17 \%)$ & $0(0 \%)$ \\
\hline Dyspnea & $6(14 \%)$ & $1(2 \%)$ & $10(24 \%)$ & $4(10 \%)$ \\
\hline Oropharynx pain & $2(5 \%)$ & $0(0 \%)$ & $5(12 \%)$ & $0(0 \%)$ \\
\hline Alopecia & $6(14 \%)$ & $0(0 \%)$ & $4(10 \%)$ & $0(0 \%)$ \\
\hline Rash & $6(14 \%)$ & $0(0 \%)$ & $1(2 \%)$ & $0(0 \%)$ \\
\hline Hypotension & $5(12 \%)$ & $2(5 \%)$ & $6(15 \%)$ & $0(0 \%)$ \\
\hline Pyrexia & $6(14 \%)$ & $0(0 \%)$ & $6(15 \%)$ & $0(0 \%)$ \\
\hline
\end{tabular}

Oral Oncol. Author manuscript; available in PMC 2016 May 05. 